\title{
Transaxillary Endoscopic Thyroidectomy: An Early Learning Experience from Singapore
}

\author{
Anil D Rao ${ }^{1}$, Saleem AA Kareem² ${ }^{2}$ Clement Chia ${ }^{3}$, Reyaz M Singaporewalla ${ }^{4}$
}

\begin{abstract}
Background: The pursuit of cosmesis and patient satisfaction has led surgeons to push the boundaries of minimally invasive thyroid surgery. We studied the feasibility, results, cosmesis, and patient satisfaction with scarless endoscopic thyroidectomy (SET) using an axillary-breast approach with particular emphasis on initial learning outcomes.

Materials and methods: Between January 2016 and 2017, 13 patients $(M=3, F=10)$ who met the eligibility criteria that included symptomatic unilateral benign nodules $<6 \mathrm{~cm}$ (cyst, follicular neoplasm, adenomatous goiter), multinodular goiter, and differentiated microcarcinoma with low risk were offered endoscopic hemithyroidectomy for unilateral disease. Nodules larger than $6 \mathrm{~cm}$, substernal goiter, patients with previous neck surgery, malignancy, and Graves' disease were excluded. All patients underwent ultrasound evaluation of the thyroid and breast. In our approach (Unilateral Axillary Breast Approach), the 10-mm camera port was placed via the anterior axillary fold with two working $5 \mathrm{~mm}$ ports via the ipsilateral shoulder and circumareolar region.

Results: Mean operating time was 133 minutes (85-180), with a mean blood loss of $40 \mathrm{~mL}(25-75)$. There were no conversions or major complications. One patient experienced transient voice change with complete recovery in 3 weeks. Two patients had chest wall seromas. Pain scores on the visual analog scale at recovery, 6 hours, and on the first postoperative day were $2,1.8$, and 2.3 (range 1-5, 1-3, and 1-4), respectively. The mean length of stay was 2.2 days. Seventy-seven percent (10/13) of patients rated cosmetic results and overall satisfaction as excellent (good -2 , unsatisfactory -1 ). Port insertion and flap raising times showed statistically significant improvements in the second half of the series $(p<0.01)$.

Conclusion: In selected patients, SET offers distinct cosmetic advantages and patient satisfaction with acceptable morbidity rates. It is a useful technique that a thyroid surgeon needs to have in his armamentarium in pursuit of patient-centered treatment goals. This study was performed during the inception of learning and thus is significant in terms of outcomes expected during the early learning curve of this procedure.

Keywords: Endoscopic, Learning, Scarless, Thyroidectomy, Transaxillary.

World Journal of Endocrine Surgery (2020): 10.5005/jp-journals-10002-1298
\end{abstract}

\section{INTRODUCTION}

Increasing patient concerns about cosmesis have been a primary driver to develop innovative techniques to improve cosmetic outcome after thyroidectomy. As a result, minimally invasive surgery has found an increasingly more prominent role in the realm of thyroid surgery and SET [scarless (in the neck) endoscopic thyroidectomy] is one such technique. Conventional thyroidectomy entails a skin crease incision in the neck which causes permanent scarring. In the Asian population, one of the biggest apprehensions for patients undergoing thyroid surgery is the appearance of a neck scar. The cosmetic impact of the scar can be significant and can affect the quality of life. ${ }^{1}$ The pursuit of a better cosmetic outcome has driven surgeons to shorten or eliminate the incisional scar in the neck. ${ }^{2}$ This is especially so in the female population, in whom thyroid nodules are more common, with conventional thyroidectomy leaving a debilitating neck scar. Gagner reported the first case of endoscopic neck surgery (subtotal parathyroidectomy) in 1996 and Hüscher et al. described the first endoscopic thyroidectomy in $1997 .{ }^{3,4}$ Since then, various approaches of minimal access endoscopic thyroidectomy have been developed which include thyroidectomy techniques categorized either as minimally invasive video-assisted thyroidectomy (MIVAT) and the newer SET techniques which aim to reduce or avoid neck scars. The safety and advantages of MIVAT have been well documented. It is a gasless technique performed through a single $2 \mathrm{~cm}$ incision in the neck. On the contrary, endoscopic thyroidectomy leaves no scar in the
1,3,4 Department of General Surgery, Khoo Teck Puat Hospital, Singapore ${ }^{2}$ Department of General Surgery, Tan Tock Seng Hospital, Singapore

Corresponding Author: Anil D Rao, Department of General Surgery, Khoo Teck Puat Hospital, Singapore, Phone: +65 96621104, e-mail: dranilrao70@hotmail.com

How to cite this article: Rao AD, Kareem SAA, Chia C, et al. Transaxillary Endoscopic Thyroidectomy: An Early Learning Experience from Singapore. World J Endoc Surg 2020;12(2):60-65.

Source of support: Nil

Conflict of interest: None

neck and hence is more esthetically appealing. There has been an ongoing debate about the true nature of endoscopic thyroidectomy being once of minimal access but maximally invasive. In this sense, endoscopic thyroidectomy differs from other minimally invasive approaches and has several risks inherent with a technically difficult new procedure. This paper deals with the experience and learning outcomes during the early learning curve of endoscopic thyroidectomy that every surgeon should be aware of.

\section{Materials and Methods}

After institutional review board approval, 13 patients who underwent endoscopic hemithyroidectomy (ETH) using the axillarybreast approach, were evaluated retrospectively over a 1-year

(c) The Author(s). 2020 Open Access This article is distributed under the terms of the Creative Commons Attribution 4.0 International License (https://creativecommons. org/licenses/by-nc/4.0/), which permits unrestricted use, distribution, and non-commercial reproduction in any medium, provided you give appropriate credit to the original author(s) and the source, provide a link to the Creative Commons license, and indicate if changes were made. The Creative Commons Public Domain Dedication waiver (http://creativecommons.org/publicdomain/zero/1.0/) applies to the data made available in this article, unless otherwise stated. 
period (January 2016-2017). All patients underwent ultrasound (US) evaluation of the thyroid and female patients had additional US breast before surgery. Eligibility criteria for ETH included unilateral symptomatic solid or cystic benign thyroid lesions measuring up to $5 \mathrm{~cm}$ in maximum diameter. Patients with nodules larger than 5 $\mathrm{cm}$, bilateral diffuse goiters, retrosternal goiter, malignant nodules, history of previous neck surgery, and Graves' disease were excluded. Intraoperative nerve monitoring (IONM) was not used for any of the cases.

Data collected included patient demographics, indication for surgery, preoperative diagnosis, operating time, successful visualization of the recurrent laryngeal nerve (RLN), specimen size, final histology, pain scores using visual analog scale (VAS), length of stay, and complications. The cosmetic results and patient satisfaction scores were evaluated via a telephone survey by an independent assessor using a three-point Likert scale 3 months post-surgery. Cumulative timings for port insertion and raising of flaps were also compared between the second and first half of the series.

\section{TeCHNIQUe}

Under general anesthesia, the patient is placed supine with neck extension, both arms abducted at $90^{\circ}$ and head turned to side contralateral to the site of the lesion. A $10-\mathrm{mm}$ camera port is inserted via a skin incision over the anterior axillary line after initial blunt trocar insertion in the subcutaneous supra-pectoral plane. The other two 5-mm ports are then inserted under direct vision via skin incisions in the ipsilateral shoulder and circumareolar region of the ipsilateral breast at 2 o'clock position (Fig. 1). Flaps are raised in
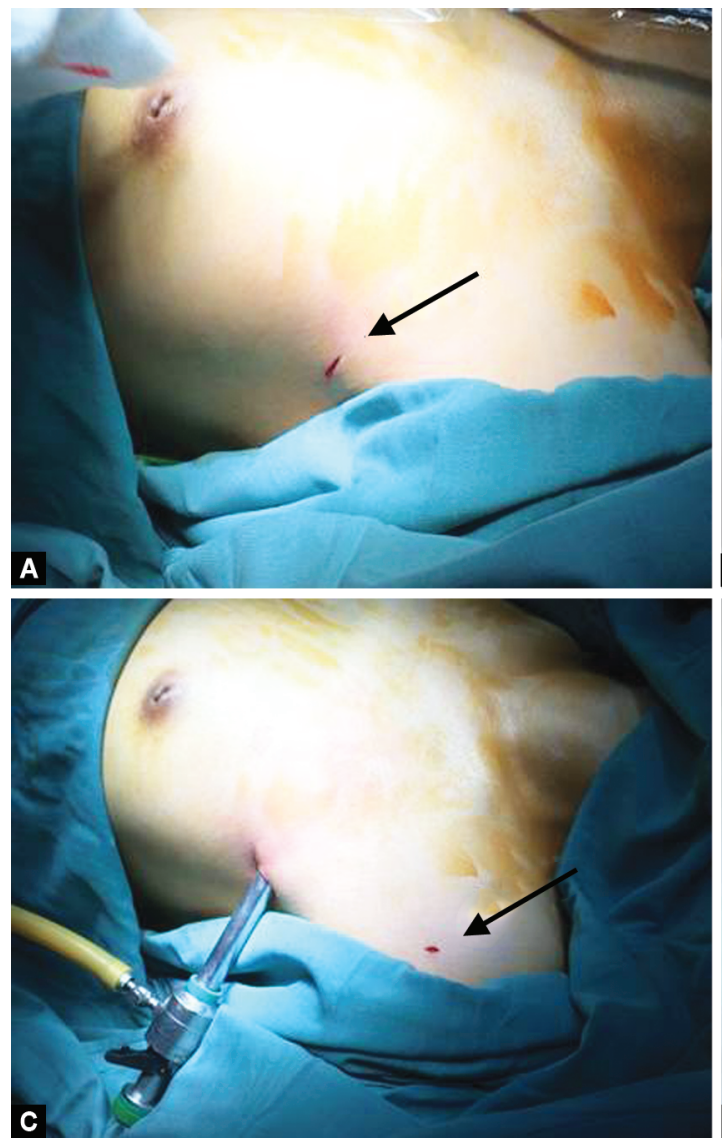

Figs $1 \mathrm{~A}$ to $\mathrm{D}$ : Port placements the layer just above the pectoralis major fascia using a combination of diathermy and energy device dissection under the vision of the endoscope. The white aponeurotic plane between yellow subcutaneous fat and underlying pectoral muscle fascia serves to guide the right plane of dissection. This is particularly vital, to avoid a tethered appearance in the area of skin overlying the flap (Figs 2 and 3). The pectoral muscle perforators are carefully isolated and divided using the energy device. The first landmark after adequate superomedial dissection is the sternal notch. The limit of medial flap raising dissection is till the opposite sternocleidomastoid (SCM) after identifying the tendon of insertion of the ipsilateral SCM. The superior dissection is carried out in a plane below the platysma up to the superior border of the thyroid cartilage and laterally till close to the lateral margin of the ipsilateral SCM. This way our dissection avoids entry between the two heads of the SCM as has been described by some other centers. Most of the dissection is carried out with diathermy. Occasional bleeding from tributaries of the anterior jugular can be arrested with the energy device. After creating an adequate neck space, the anterior border of the SCM and omohyoid is dissected to further expose the thyroid gland margins. The superior belly of the omohyoid muscle is divided if the gland size needs additional exposure. The two layers of overlying strap muscles are incised longitudinally with hook diathermy to expose the surface of the thyroid lobe. The dissection then proceeds to separate the strap muscles from the surface of the gland and approach the superior pole. Similarly, the lower pole is exposed by blunt dissection and retraction to identify the tracheal landmark. The parathyroid glands are identified and dissected off. The tracheaesophageal groove is exposed to identify the RLN with blunt
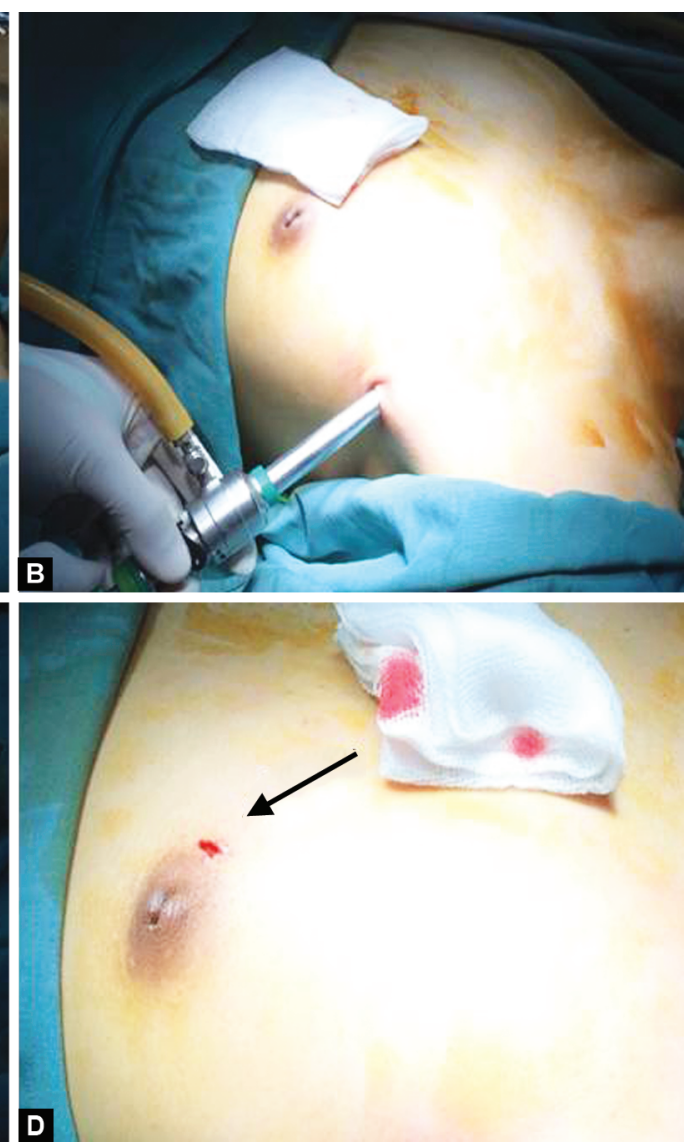


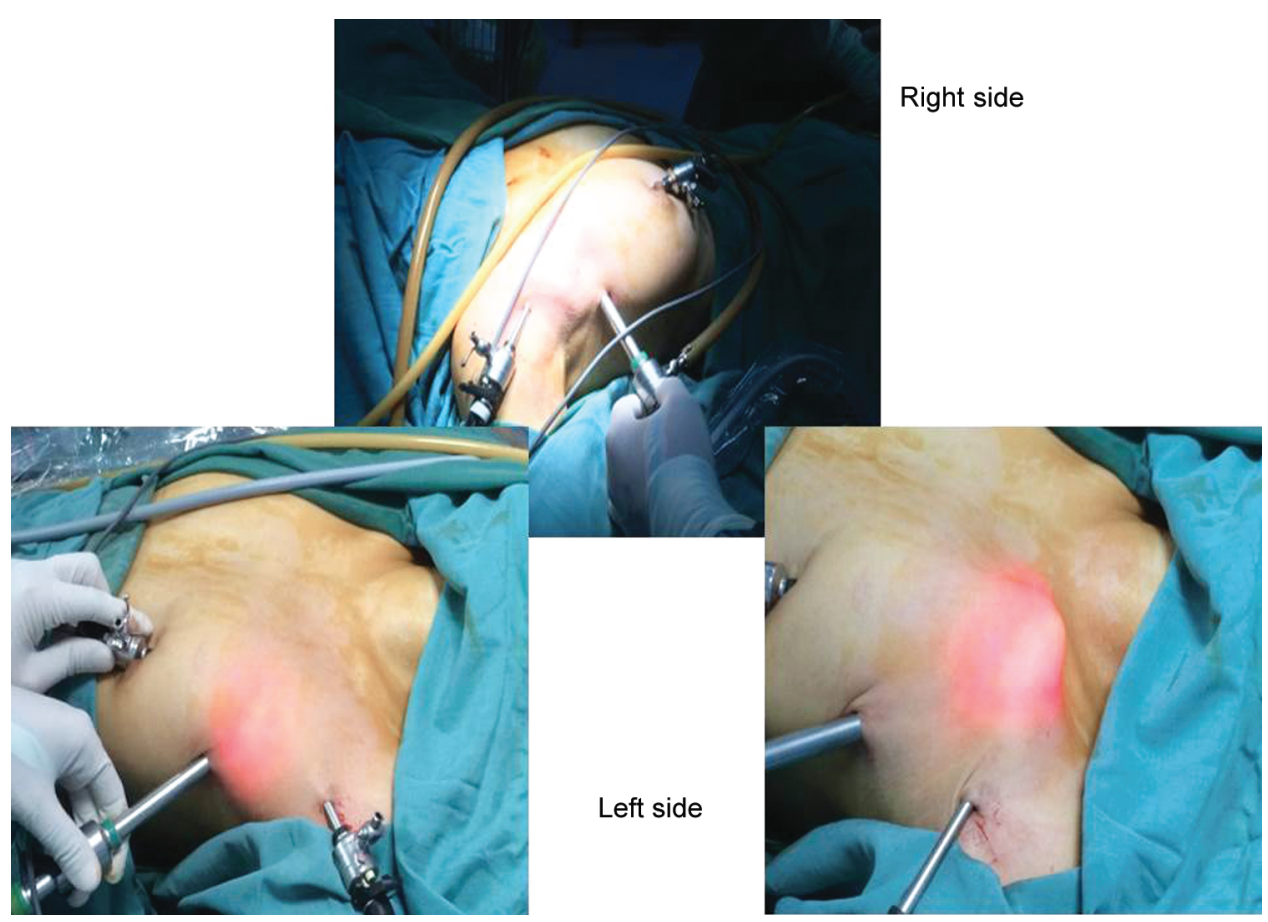

Fig. 2: Flap creation
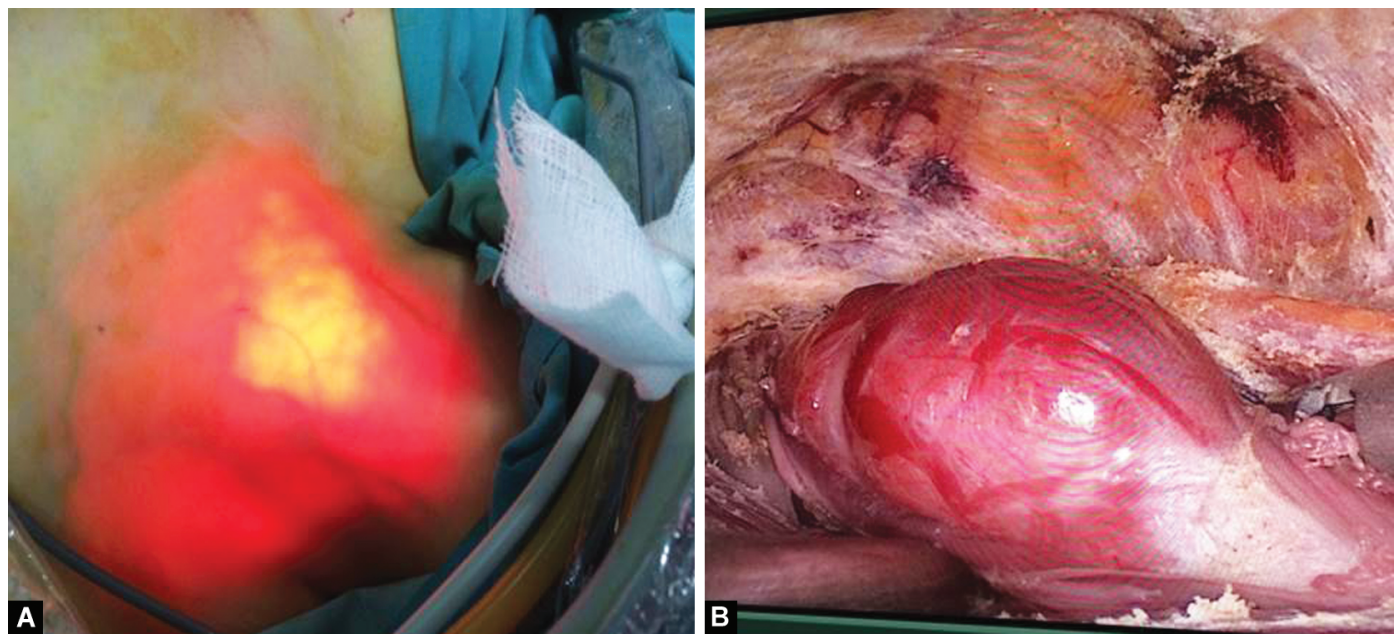

Figs $3 \mathrm{~A}$ and B: Optimal flap dissection and space creation

dissection following which the thyroid gland is dissected off the tracheal surface leaving behind a tiny rim of the thyroid along the suspensory ligament. The specimen is removed whole using a sterile plastic bag. Hemostasis is assured with a Valsalva maneuver before inserting a Radivac size 10 drain under direct vision. Lignocaine $1 \%$ is infiltrated into wound edges before skin closure.

\section{Results}

During the 1-year period between January 2016 and January 2017, 13 patients ( 10 female, $77 \%$ ) underwent ETH. Patient demographics, nodule size, and histology are presented in Table 1. There were no conversions to conventional open surgery due to technical difficulty. The other operative details are shown in Table 2. Blood loss was minimal. The mean operating time was 137 minutes. Port insertion and flap raising times assessed as a cumulative sum
Table 1: Demographics, nodule size, and histology

\begin{tabular}{ll}
\hline Demographics & \\
$\quad$ Age, years & $41.5(17-59)$ \\
Sex ratio (female:male) & $3.33: 1$ \\
Nodule size, cm & $3.2(1.8-5)$ \\
Final histology & Patients, $n(\%)$ \\
Multinodular colloid goiter & $5(38.4 \%)$ \\
Solitary hyperplastic/adenomatous nodule & $3(23.7 \%)$ \\
Degenerating cyst & $5(38.4 \%)$ \\
\hline
\end{tabular}

showed a progressive improvement in the second half of the series and this was statistically significant $(p<0.01)$. All patients had their drains removed on a postoperative day (POD) 3 after clinic review. The mean length of stay was 2.2 days (range $2-3$ ). One patient 
Table 2: Operative details

\begin{tabular}{ll}
\hline $\begin{array}{l}\text { Blood loss, } \mathrm{mL} \\
\text { Duration, minutes }\end{array}$ & $40(25-75)$ \\
Total operative duration & $137(99-180)$ \\
Port insertion for first 6 cases & $19(15-20)$ \\
Flap rising for first 6 cases & $52(44-65)$ \\
Port insertion for last 7 cases & $13(10-19)$ \\
Flap rising for last 7 cases & $33(25-38)$ \\
RLN identification, $n(\%)$ & $7(53.8 \%)$ \\
\hline
\end{tabular}

experienced transient hoarseness of voice which recovered fully on POD 10. There were no cases with permanent voice change. Other minor complications were seen in three patients (neck paresthesia-1, neck seroma-2). The neck seromas responded to aspiration and the only case with protracted neck paresthesia has since recovered fully at 6 months of follow-up. Pain scores at recovery, 6 hours, and on first POD were 2, 1.8, and 2.3 (range 1-5, $1-3$, and 1-4), respectively. The average pain score at clinic follow-up was $1.6(0-4)$ with complete resolution of any residual chest wall paresthesia and numbness. The mean duration of follow-up was 6.3 months (3-11). All patients were administered a telephone survey at 3 months of follow-up by an independent nurse clinician to grade overall performance of their procedure in terms of cosmetic and overall patient satisfaction into one of the three, namely excellent, good, and unsatisfactory. There was a $100 \%$ response rate. Ten out of 13 graded their experience as excellent with 2 grading it as good and 1 as unsatisfactory. The patient who graded it as unsatisfactory experienced protracted paresthesia and some degree of sharp pain on neck movement. As mentioned earlier, this has, however, completely resolved on long-term follow-up.

\section{Discussion}

The American Thyroid Association (ATA) statement on remote access thyroid surgery classifies it into four broad groups, namely:

- Endoscopic Breast Approach.

- Endoscopic (and Robotic) Bilateral Axillo-breast Approach.

- Endoscopic (and Robotic) Axillary Approach.

- Endoscopic (and Robotic) Facelift Approach. ${ }^{5}$

Each of these approaches has its inherent advantages and disadvantages. Ikeda et al. described a 3-port axillary approach in 2002 which achieved excellent cosmetic results. ${ }^{6}$ However, due to the proximity of the ports, there was significant interference between surgical instruments leading to protracted operating times. A 3-port endoscopic breast approach was described by Ohgami et al. which led to an improvement in surgical field access with narrow angled instrumentation. ${ }^{7}$ To overcome surgical instrumentation difficulties, avoid parasternal scars, and shorten operative times, the axillo-bilateral breast approach was introduced by Shimazu et al. as a hybrid technique. ${ }^{8}$ Despite favorable cosmetic results and easier instrumentation, it was difficult to expose the whole thyroid and to handle the contralateral breast port. As a result, Choi et al. developed a bilateral axillo-breast approach (BABA) to simplify total thyroidectomy, this, however, requires the elevation of a wider skin flap. ${ }^{9}$ Gasless endoscopic surgeries including facelift techniques have also been in the fray for some time now. ${ }^{10}$ The indications and contraindications to SET are still unclear and are in a state of continuous evolution. Generally, the accepted contraindications are as follows:
- A malignant tumor with lymph node metastasis was diagnosed preoperatively.

- A large volume nodule (>60 mm).

- History of previous neck surgery.

- Substernal nodular goiter.

- Graves' disease.

In this paper, we describe our initial experience with endoscopic hemithyroidectomy via the axillary-breast approach in Singapore. Although endoscopic procedures have attracted significant attention due to improved cosmetic outcome, the authors postulate that widespread acceptance may be currently deterred by the steep technical learning curve involved as well as the continually evolving experience. The mean operating time in our series was 137 minutes. This serves to emphasize the initial difficulties encountered during the learning phase of any new procedure. We believe that endoscopic thyroidectomy requires considerable laparoscopic and minimal access surgical experience. The authors believe that the performance of endoscopic thyroidectomy to be akin to that of minimally invasive extraperitoneal type hernia repairs in that the skill-sets acquired from conventional thyroidectomy is not immediately transferrable to that of endoscopic thyroid surgery. This procedure is expected to have a significant learning curve and should ideally be attempted only by surgeons with excellent laparoscopic skills and those well versed with thyroid anatomy. The authors also believe that the anatomical knowledge gained while performing the lateral "backdoor" open thyroidectomy will significantly help while performing ETH using our technique. ${ }^{11}$

Liu et al. demonstrated that the first 60 cases of endoscopic thyroidectomy constitute the early stage of the learning phase. Proficiency and stability of the operation are only reached after 150 cases. ${ }^{12}$ A steep gradient followed by a long plateau represents the initial portion of the typical learning curve. ${ }^{13}$ Given our initial experience in endoscopic thyroidectomy, it appears that we are still in the early stage of the learning curve. In our study, we evaluated two key steps, namely port insertion and flap raising times to evaluate our progress. The authors consider efficient and accurate port insertion and good flap raising to be the key steps in determining ease of performance in this surgical procedure. The port insertion and flap raising times assessed as a cumulative sum showed a progressive improvement in the second half of the series. This is a significant take-home message in this initial experience study as it does show a steady and significant improvement in operating times in these two key steps, especially after about six consecutive cases. We believe that as experience evolves, additional parameters like the rate of accurate visual identification of the RLNs must be taken as additional benchmarks to judge performance. Pons et al. have shown that as few as the first 10 cases can represent the early phase of the learning curve. ${ }^{14}$

Pain is a subjective phenomenon affected by multiple variables including patient, surgeon, and disease factors. SET involves a much larger area of tissue dissection and may entail pain and tissue bruising in the postoperative period, thus being labeled by some experts as "minimal access, but maximally invasive".,15 Reports have also suggested an increased risk of postoperative pain over the ipsilateral shoulder in view of being in a prolonged abducted position during surgery, however, this usually resolves by POD $7 .{ }^{16}$ A prospective study by Ryu et al. comparing pain scores of patients undergoing SET and conventional surgery did not show any significant difference between VAS scores except in the ipsilateral shoulder and central neck. The pain scores in 
the central neck were higher in the conventional thyroidectomy group; however, pain scores in the shoulder were higher in the SET group. ${ }^{16}$ Most patients, who experience moderate to severe pain, do so on POD $1 .^{17}$ In our series, the VAS pain scores at recovery, 6 hours post-surgery, and POD 1 are 2, 1.8, and 2.3, respectively, which are excellent results and tend to be similar or even lower than that reported by some authors. ${ }^{16}$ The patients in our series received regular paracetamol and etoricoxib. In addition, all patients were reviewed by the physiotherapist to teach shoulder exercises before discharge. A multidisciplinary team approach with the use of multimodal analgesia with careful consideration of operative conduct will yield the best pain control results. The authors' pilot experience in a high-volume unit has shown better pain scores in endoscopic thyroidectomy compared with conventional cases which can be attributed to more precise dissection and shorter duration of surgery in experienced hands.

Many experts have criticized SET for increasing postoperative pain and extending drain insertion, and resulting in a longer hospital stay, as compared with conventional open surgery. In our series, save for one patient, all patients were discharged on the day after surgery with drain in situ. Drains were removed after clinic review on POD 3. It is the authors' view that SET is still in its infancy and as surgeons gain more experience and get ahead of the learning curve the outcomes will improve. Already some papers have shown pain, inflammatory response, and human function to be at par when performed in high volume centers. ${ }^{18}$ Some recent literature reports have shown no differences in biochemical markers such as inflammatory markers and acid-base responses between endoscopic and conventional thyroidectomy. ${ }^{19}$ The initial discomfort, skin bruising or seroma, and longer period of postoperative drains may be a small price to pay for many patients if the long-term benefits of avoiding a neck scar altogether is an important consideration. The overall complication rate of endoscopic thyroidectomy has been reported to be similar to conventional thyroidectomy since its inception. ${ }^{20}$ The main complications of SET are similar to that of conventional thyroidectomy and include injury to the RLN, parathyroid gland, hematoma, and seroma formation. However, some are unique to all SET approaches. There is a higher incidence of skin paresthesia which is due to the extensive flap elevation required to achieve an adequate operative field. This is also responsible for the higher seroma rates. In our series, one patient (7.6\%) had skin paresthesia that resolved after 6 months. Two patients (15.3\%) had seroma which was managed conservatively.

The incidence of transient or permanent injury to the RLN varies from 0 to $10 \% .^{2}$ We have so far had only one patient with postoperative hoarseness. This was transient and the patient recovered fully. Endoscopic thyroidectomy may provide a highly magnified view of the thyroid anatomy, including the parathyroid glands and the RLN, but complications such as RLN injury have been attributed to thermal injury because of ultrasonic shears. ${ }^{21}$ In our series, the overall RLN visualization rate was $53.8 \%$ which is lower than that reported by other authors. ${ }^{22}$ We believe that as the authors gain further experience in this technique the visualization rates will also improve. Intraoperative nerve monitoring may also help to improve RLN identification rates and we have an ongoing study evaluating its usefulness in SET. Other complications unique to this procedure like severe subcutaneous emphysema and hypercarbia are known to be associated with relatively high $\mathrm{CO}_{2}$ insufflation pressures $(>20 \mathrm{~mm} \mathrm{Hg})$, while low insufflation pressures
(5-8 $\mathrm{mm} \mathrm{Hg}$ ) have rarely been associated with hypercarbia, extensive emphysema, and gas embolism. ${ }^{23,24}$ Rare complications have been described with endoscopic thyroidectomy such as tract site recurrence of thyroid neoplasm. ${ }^{25-27}$ Most differentiated thyroid cancers follow an indolent course with a good prognosis and are thus generally amenable to endoscopic approaches at an early stage. There have been no randomized clinical trials or comparative studies with long-term follow-up data to comment on the oncologic equivalency of remote access thyroidectomy to conventional surgery, but the data show that these procedures can be done safely in high volume centers. ${ }^{5}$ A recent meta-analysis of surgical safety and oncologic effectiveness reported remote access techniques to be associated with less estimated blood loss, better cosmetic satisfaction, and a lower level of swallowing impairment. ${ }^{28}$ In a recent meta-analysis by Lang et al., remote access techniques showed longer operative times, mean hospital stay, and higher transient RLN injury rates. There was, however, no difference regarding blood loss, hypocalcemia, and overall morbidity. ${ }^{29}$ In the study by Lee et al., cosmetic satisfaction at 3 months postoperatively was significantly greater in the remote access compared with the open group. ${ }^{30}$

The optimal method remains to be established. In some Asian centers, breast approach endoscopic thyroidectomy (BAET) is more widely accepted in treating benign thyroid lesions. ${ }^{31}$ Some high volume Asian centers believe that it is likely to be more accepted in the future for thyroid neoplasms. ${ }^{32}$ Scarless endoscopic thyroidectomy is technically challenging and has a longer learning curve. ${ }^{12}$ In the earlier days, careful patient selection played an integral role in the success of endoscopic thyroidectomy. Patients under the age of 45 who had a tumor $<3 \mathrm{~cm}$ in diameter is well suited for endoscopic thyroidectomy. However, the indications of endoscopic thyroidectomy have been extended to Graves' disease and early thyroid cancer. ${ }^{12,13}$ SET offers excellent cosmesis outcomes compared with conventional thyroidectomy. Its benefits are best appreciated when the patient is appropriately selected for the procedure and performed by a trained surgeon in endoscopic thyroidectomy. This new surgical technique remains in the early stage of the learning curve with many surgeons still lacking sufficient clinical experience. However, in carefully selected patients, the distinct cosmetic advantages and patient satisfaction that SET offers may drive its more widespread adoption. The authors consider the outcomes of this early learning curve experience pivotal in guiding newcomers to this, as yet evolving field of minimal access thyroid surgery.

\section{References}

1. Holme $S$, Beattie P, Fleming C. Cosmetic camouflage advice improves quality of life. Br J Dermatol 2002;147(5):946-949. DOI: 10.1046/j.13652133.2002.04900.x.

2. Tan C, Cheah W, Delbridge L. "Scarless" (in the neck) endoscopic thyroidectomy (SET): an evidence-based review of published techniques. World J Surg 2008;32(7):1349-1357. DOI: 10.1007/s00268008-9555-3.

3. Gagner M. Endoscopic subtotal parathyroidectomy in patients with primary hyperparathyroidism. Br J Surg 1996;83(6):875-875. DOI: 10.1002/bjs.1800830656.

4. Lirici MM, Hüscher CSG, Chiodini S, et al. Endoscopic right thyroid lobectomy. Surg Endosc 1997;11(8):877. DOI: 10.1007/s004649900476. http://www.ncbi.nlm.nih.gov/pubmed/9266657.

5. Berber E, Bernet V, Fahey TJ, et al. American Thyroid Association statement on remote-access thyroid surgery. Thyroid 2016;26(3):331337. DOI: $10.1089 /$ thy.2015.0407. 
6. Ikeda $\mathrm{Y}$, Takami H, Niimi M, et al. Endoscopic thyroidectomy and parathyroidectomy by the axillary approach. Surg Endosc Other Interv Tech 2002;16(1):92-95. DOI: 10.1007/s004640080175.

7. Ohgami M, Ishii S, Arisawa Y, et al. Scarless endoscopic thyroidectomy: breast approach for better cosmesis. Surg Laparosc Endosc Percutan Tech 2000;10(1):1-4. DOI: 10.1097/00129689-200002000-00001. http://www.ncbi.nlm.nih.gov/pubmed/10872517.

8. Shimazu K, Shiba E, Tamaki Y, et al. Endoscopic thyroid surgery through the axillo-bilateral-breast approach. Surg Laparosc Endosc Percutan Tech 2003;13(3):196-201. DOI: 10.1097/00129689200306000-00011.

9. Choi JY, Lee KE, Chung KW, et al. Endoscopic thyroidectomy via bilateral axillo-breast approach (BABA): review of 512 cases in a single institute. Surg Endosc Other Interv Tech 2012;26(4):948-955. DOI: 10.1007/s00464-011-1973-x.

10. Terris DJ, Singer MC, Seybt MW. Robotic facelift thyroidectomy. Surg Laparosc Endosc Percutan Tech 2011;21(4):237-242. DOI: 10.1097/ SLE.0b013e3182266dd6.

11. Singaporewalla RM, Tan BC, Rao AD. The lateral "backdoor" approach to open thyroid surgery: a comparative study. Asian J Surg 2018;41(4):384-388. DOI: 10.1016/j.asjsur.2017.05.003.

12. Liu S, Qiu M, Jiang DZ, et al. The learning curve for endoscopic thyroidectomy: a single surgeon's experience. Surg Endosc Other Interv Tech 2009;23(8):1802-1806. DOI: 10.1007/s00464-009-0332-7.

13. Li JCM, Lo AWI, Hon SSF, et al. Institution learning curve of laparoscopic colectomy - a multi-dimensional analysis. Int J Colorectal Dis 2012;27(4):527-533. DOI: 10.1007/s00384-011-1358-6.

14. Pons $Y$, Vérillaud B, Blancal J-P, et al. Minimally invasive video-assisted thyroidectomy: learning curve in terms of mean operative time and conversion and complication rates. Head Neck 2013;35(8):1078-1082. DOI: 10.1002/hed.23081.

15. Takami H, Ikeda Y, Hsu B, et al. Total endoscopic thyroidectomy. Asian J Surg 2003;26(2):82-85. DOI: 10.1016/S1015-9584(09)60226-8.

16. Ryu HR, Lee J, Park JH, et al. A comparison of postoperative pain after conventional open thyroidectomy and transaxillary singleincision robotic thyroidectomy: a prospective study. Ann Surg Oncol 2013;20(7):2279-2284. DOI: 10.1245/s10434-012-2557-2.

17. Ikeda $Y$, Takami H, Sasaki $Y$, et al. Clinical benefits in endoscopic thyroidectomy by the axillary approach. J Am Coll Surg 2003;196(2):189-195. DOI: 10.1016/S1072-7515(02)01665-4.

18. Jiang Z, Zhang W, Jiang $D$, et al. Clinical benefits of scarless endoscopic thyroidectomy: an expert's experience. World J Surg 2011;35(3):553557. DOI: $10.1007 / \mathrm{s} 00268-010-0905-6$.

19. Wang M, Zhang T, Mao Z, et al. Effect of endoscopic thyroidectomy via anterior chest wall approach on treatment of benign thyroid tumors. J Laparoendosc Adv Surg Tech A 2009;19(2):149-152. DOI: 10.1089/lap.2008.0296.
20. Yeung GHC. Endoscopic thyroid surgery today: a diversity of surgical strategies. Thyroid 2002;12(8):703-706. DOI: 10.1089/105072502760258677.

21. Inabnet III WB, Jacob BP, Gagner M, et al. Minimally invasive endoscopic thyroidectomy by a cervical approach. Surg Endosc 2003;17(11):1808-1811. DOI: 10.1007/s00464-002-8760-7.

22. Lv B, Zhang B, Zeng Q. Total endoscopic thyroidectomy with Intraoperative laryngeal nerve monitoring. Int J Endocrinol 2016;2016:7381792. DOI: 10.1155/2016/7381792.

23. Gottlieb A, Sprung J, Zheng XM, et al. Massive subcutaneous emphysema and severe hypercarbia in a patient during endoscopic transcervical parathyroidectomy using carbon dioxide insufflation. Anesth Analg 1997;84(5):1154-1156. DOI: 10.1213/00000539$199705000-00040$.

24. Brunt LM, Jones DB, Wu JS, et al. Experimental development of an endoscopic approach to neck exploration and parathyroidectomy. Surgery 1997;122(5):893-901. DOI: 10.1016/S0039-6060(97)90330-5. http://www.ncbi.nlm.nih.gov/pubmed/9369889.

25. Beninato T, Kleiman DA, Scognamiglio T, et al. Tract recurrence of a follicular thyroid neoplasm following transaxillary endoscopic thyroidectomy. Thyroid 2012;22(2):214-217. DOI: 10.1089/ thy.2011.0395.

26. Hur SM, Kim SH, Lee SK, et al. Is a thyroid follicular neoplasm a good indication for endoscopic surgery? Surg Laparosc Endosc Percutan Tech 2011;21(3):e148-e151. DOI: 10.1097/SLE.0b013e31821aaa60.

27. Kim JH, Choi YJ, Kim JA, et al. Thyroid cancer that developed around the operative bed and subcutaneous tunnel after endoscopic thyroidectomy via a breast approach. Surg Laparosc Endosc Percutan Tech 2008;18(2):197-201. DOI: 10.1097/SLE.0b013e318168dda4.

28. Son SK, Kim JH, Bae JS, et al. Surgical safety and oncologic effectiveness in robotic versus conventional open thyroidectomy in thyroid cancer: a systematic review and meta-analysis. Ann Surg Oncol 2015;22(9):3022-3032. DOI: 10.1245/s10434-015-4375-9.

29. Lang $\mathrm{BHH}$, Wong $\mathrm{CKH}$, Tsang JS, et al. A systematic review and meta-analysis comparing surgically-related complications between robotic-assisted thyroidectomy and conventional open thyroidectomy. Ann Surg Oncol 2014;21(3):850-861. DOI: 10.1245/ s10434-013-3406-7.

30. Lee J, Nah KY, Kim RM, et al. Differences in postoperative outcomes, function, and cosmesis: open versus robotic thyroidectomy. Surg Endosc 2010;24(12):3186-3194. DOI: 10.1007/s00464-010-1113-z.

31. Zhang W, Jiang D, Liu S, et al. Current status of endoscopic thyroid surgery in China. Surg Laparosc Endosc Percutan Tech 2011;21(2):6771. DOI: $10.1097 /$ SLE.0b013e318213961d.

32. Bae JS, Cho YU, Sung GY, et al. The current status of endoscopic thyroidectomy in Korea. Surg Laparosc Endosc Percutan Tech 2008;18(3):231-235. DOI: 10.1097/SLE.0b013e31816907do. 